\title{
Epidemiology of Dermatophytoses in Switzerland According to a Survey of Dermatophytes Isolated in Lausanne between 2001 and 2018
}

\author{
Olympia Bontems ${ }^{1}$, Marina Fratti ${ }^{1}$, Karine Salamin ${ }^{1}$, Emmanuella Guenova ${ }^{1,2}$ D \\ and Michel Monod 1,2,* \\ 1 Service de Dermatologie, Laboratoire de Mycologie, Centre Hospitalier Universitaire Vaudois, \\ 1011 Lausanne, Switzerland; Olympia.Bontems@chuv.ch (O.B.); Marina.Fratti@chuv.ch (M.F.); \\ Karine.Salamin@chuv.ch (K.S.); Emmanuella.Guenova@chuv.ch (E.G.) \\ 2 Faculty of Biology and Medicine, University of Lausanne, 1015 Lausanne, Switzerland \\ * Correspondence: Michel.Monod@chuv.ch; Tel.: +41-21-314-0376; Fax: +41-21-314-0378
}

Received: 2 June 2020; Accepted: 24 June 2020; Published: 26 June 2020

\begin{abstract}
Dermatophytes are the most common pathogenic agents of superficial mycoses in humans and animals. Knowledge of their epidemiology can facilitate the prevention of dermatophytosis and improve prophylactic measures. We sought to determine the incidence of the different dermatophyte species diagnosed in Lausanne (Switzerland) from 2001 to 2018. In total, 10,958 dermatophytes were isolated from patients and 459 from pets. Overall, 99\% of tinea unguium and tinea pedis were caused by Trichophyton rubrum and Trichophyton interdigitale with a prevalence ratio of 3:1. Trichophyton violaceum and Trichophyton soudanense were mainly found in tinea capitis in patients of African and Mediterranean origin. Interestingly, while Epidermophyton floccosum and Trichophyton verrucosum were prevalent 50 years ago in an epidemiological analysis carried out in the same laboratory from 1967 to 1970, these two species were rarely detected from 2001 to 2018. Trichophyton mentagrophytes, Trichophyton benhamiae and Microsporum canis were the prevalent zoophilic pathogenic species in children and young adults. Our investigation of animal samples revealed the main reservoirs of these zoophilic species to be cats and dogs for T. mentagrophytes and M. canis, and Guinea pigs for T. benhamiae. This study provides an epidemiological overview of dermatophytoses in Switzerland to improve their surveillance.
\end{abstract}

Keywords: Trichophyton; Microsporum; Epidermophyton; epidemiology; dermatophytosis onychomycosis; tinea pedis

\section{Introduction}

Most superficial mycoses are caused by dermatophytes, which infect the stratum corneum of the epidermis, nails and hair. Healthy individuals usually develop a dermatophyte-induced infection at least once during their lifetime, and dermatophytosis is a daily encounter for dermatologists. Accurate dermatophyte identification at the species level is important for both tracking the source of infection and for the initiation of an appropriate treatment [1-3]. For example, while the cure rate for tinea capitis caused by the anthropophilic species Trichophyton violaceum and Trichophyton soudanense is excellent with systemic terbinafine, griseofulvin remains the treatment of choice for other scalp ringworms. Especially, tinea capitis caused by the anthropophilic Microsporum audouinii and those caused by zoophilic dermatophytes such as Microsporum canis and Trichophyton mentagrophytes were revealed to be insensitive to terbinafine [1-3].

The prevalence of dermatophyte species continuously evolved from the middle of the 19th century until the present day, and varies depending on the geographic location of the populations [4,5]. 
The evolution of urban and rural populations, the migration to and from different continents, changes in the human lifestyle, the increasing number of pets and the medical approach to dermatophytosis in different healthcare systems are all factors that account for the observed variable prevalence of dermatophytes amongst different geographical locations. The assessment of the prevalence of pathogenic dermatophyte species and related clinical manifestations is essential and indispensable for good epidemiological surveillance.

Here, we present a comprehensive analysis on all dermatophyte species isolated from human skin and cutaneous appendage lesions referred to the mycology laboratory of the Department of Dermatology at the University Hospital in Lausanne from 2001 to 2018. Additionally, all dermatophyte species isolated from animal lesions and referred to the same department between 2008 to 2018 were included in the analysis. This large data collection, spanning over almost two decades, reveals the current trends in the epidemiology of dermatophyte infections in Switzerland, with a major focus on onychomycosis and common reservoirs of zoophilic fungal species. Comparison of the data with an epidemiological analysis carried out in the same laboratory from 1967 to 1970 showed a change in the prevalence of dermatophyte species in Switzerland over the last 50 years.

\section{Material and Methods}

\subsection{Processing of Clinical Samples}

Skin, nail and hair samples were obtained from patients presenting lesions clinically suspected of fungal infections. All patients consulted a hospital-based physician or a private practitioner in the south-western or Italian part of Switzerland who referred the dermatological samples for diagnostic analysis to our laboratory. Since 2008, animal samples, mainly hair and/or skin scales, have been included in the analysis as well. First, a part of each sample was used for immediate direct mycological examination by fluorescence microscopy [6,7]. In parallel, two culture assays in test tubes were set up. The first tube contained Sabouraud's agar medium with chloramphenicol $(50 \mu \mathrm{g} / \mathrm{mL})$, and the second tube contained Sabouraud's agar medium with chloramphenicol plus cycloheximide $(400 \mu \mathrm{g} / \mathrm{mL})$. The inoculated tubes were incubated at $30{ }^{\circ} \mathrm{C}$. Dermatophytes and moulds were identified after $10-14$ days of growth by macroscopic and microscopic examination [8,9]. $28 \mathrm{~S}$ rRNA gene and ITS sequencing were performed as previously described $[10,11]$ when dermatophyte species in cultures could not be identified with certainty based exclusively on their morphological appearance. All data were stored in a MOLIS laboratory information system (CompuGroup Medical [CGM] Lab Belgium NV, Barchon, Belgium).

\subsection{Nomenclature for Dermatophyte Species Used in This Analysis}

The results from our analysis follow the nomenclature adopted in the recent revision of the taxonomy of dermatophytes, and supported by an international expert group of authors [12]. Based on previous studies $[10,13]$, Trichophyton interdigitale was used for isolates of tinea pedis and tinea unguium, while T. mentagrophytes was used for isolates from another location (mainly tinea capitis and tinea corporis). Mating experiments as well as $28 \mathrm{~S}$ and ITS sequencing unambiguously allowed the distinction of these two species causing distinct dermatophytoses. The closely related geophilic species Nannizzia gypsea (formerly Microsporum gypseum), Nannizzia fulva and Nannizzia incurvata, all three producing numerous spindle-shaped macroconidia [14], were not distinguished. The first name was used for the analysis reports.

\section{Results}

\subsection{Dermatophytes Isolated from Patients}

In total, 77,716 dermatological samples were referred to our laboratory for mycological analysis from 2001 to 2018. The number of isolated dermatophytes was 10,958. Yeasts and moulds were found 
in 6486 and 8945 culture assays, respectively (Table 1). In onychomycosis, non-dermatophytic fungi may be infectious agents or transient contaminants. Noteworthily, Fusarium spp. and Acremonium spp. were revealed in $76 \%$ of cases when they grew as single species in culture assays [7].

The prevalence of isolated dermatophyte species and their predilection for certain body areas is shown in Table 1. Tinea unguium and tinea pedis were almost exclusively caused by Trichophyton rubrum and T. interdigitale with a prevalence ratio of about 3:1. Due to the high number of patients referred to our department of dermatology for onychomycosis, T. rubrum and T. interdigitale were the most frequently isolated dermatophytes $(61.2 \%$ and $20.1 \%$ of the total of dermatophytes, respectively). Other anthropophilic species (Trichophyton tonsurans, T. violaceum, T. soudanense, M. audouinii, and Epidermophyton floccosum) were isolated with a frequency established between 0.4 and $2.2 \%$. T. violaceum, T. soudanense and T. tonsurans were mainly from tinea capitis. Patients with T. violaceum and T. soudanense were generally patients originating from Africa and the Mediterranean rim. The anthropophilic species Trichophyton schoenleinii, Trichophyton concentricum and Microsporum ferrugineum were never detected in the patient cohort.

Zoophilic species rarely caused lesions other than tinea corporis and tinea capitis. T. mentagrophytes, M. canis and Trichophyton benhamiae were the most frequently isolated. Their frequency overpassed that of T. verrucosum, which was mainly found in the rural population and isolated from tinea capitis, tinea corporis and tinea barbae. Trichophyton erinacei and Nannizzia persicolor were isolated once and five times, respectively.

Geophilic dermatophytes of the Nanizia gypsea group of species $(n=55)$ were uncommon. 
Table 1. Prevalence of different fungi in dermatological samples analyzed in this study.

\begin{tabular}{|c|c|c|c|c|c|c|c|c|c|}
\hline Fungi Identified by Cultures & $\begin{array}{c}\text { Scalp } \\
\text { (Tinea Capitis) }^{1}\end{array}$ & $\begin{array}{c}\text { Face } \\
\left(\text { Tinea Faciae) }{ }^{1}\right.\end{array}$ & $\begin{array}{c}\text { Perineum } \\
\text { (Tinea Cruris) }^{1}\end{array}$ & $\begin{array}{c}\text { Hand } \\
\left(\text { Tinea Manum) }^{1}\right.\end{array}$ & $\begin{array}{c}\text { Body } \\
\text { (Tinea Corporis) }^{1}\end{array}$ & $\begin{array}{c}\text { Foot } \\
\text { (Tinea Pedis) }^{1}\end{array}$ & $\begin{array}{c}\text { Nail } \\
\text { (Tinea Unguium) }^{1}\end{array}$ & Total & Percent $^{2}$ \\
\hline \multicolumn{10}{|l|}{ Dermatophytes } \\
\hline \multicolumn{10}{|l|}{ Anthropophilic species } \\
\hline T. rubrum & 13 & 38 & 338 & 100 & 259 & 1546 & 4413 & 6707 & 61.21 \\
\hline T. interdigitale & 0 & 0 & 0 & 0 & 0 & 862 & 1345 & 2207 & 20.14 \\
\hline T. violaceum & 213 & 12 & 1 & 0 & 12 & 3 & 3 & 244 & 2.22 \\
\hline T. soudanense & 134 & 3 & 3 & 3 & 28 & 5 & 21 & 197 & 1.8 \\
\hline T. tonsurans & 71 & 17 & 1 & 2 & 29 & 1 & 1 & 122 & 1.11 \\
\hline E. floccosum & 1 & 1 & 6 & 1 & 10 & 11 & 10 & 40 & 0.37 \\
\hline M. audouinii & 144 & 6 & 0 & 1 & 15 & 0 & 3 & 169 & 1.54 \\
\hline \multicolumn{10}{|l|}{ Zoophilic species } \\
\hline T. mentagrophytes & 86 & 119 & 67 & 39 & 279 & 0 & 0 & 590 & 5.38 \\
\hline T. benhamiae & 19 & 39 & 0 & 11 & 68 & 2 & 0 & 139 & 1.27 \\
\hline T. verrucosum & 27 & 24 & 1 & 6 & 49 & 4 & 2 & 113 & 1.03 \\
\hline T. erinacei & 0 & 0 & 0 & 1 & 0 & 0 & 0 & 0 & 0.01 \\
\hline M. canis & 116 & 23 & 7 & 3 & 217 & 2 & 1 & 369 & 3.37 \\
\hline N. persicolor & 0 & 1 & 0 & 0 & 3 & 0 & 1 & 5 & 0.05 \\
\hline \multicolumn{10}{|l|}{ Geophilic species } \\
\hline N. gypsea & 6 & 0 & 3 & 3 & 37 & 3 & 3 & 55 & 0.5 \\
\hline Total dermatophyte cutures & 830 & 283 & 427 & 169 & 1006 & 2439 & 5803 & 10,958 & 14.1 \\
\hline \multicolumn{10}{|l|}{$\begin{array}{l}\text { Other fungi without } \\
\text { dermatophytes }\end{array}$} \\
\hline Yeasts & 54 & 693 & 1421 & 212 & 205 & 603 & 3298 & 6486 & 8.35 \\
\hline Fusarium spp./Acremonium spp. & 2 & 2 & 2 & 2 & 3 & 70 & 1078 & 1159 & 1.49 \\
\hline Other moulds & 219 & 112 & 73 & 255 & 359 & 931 & 6996 & 8945 & 11.51 \\
\hline Total positive fungal cultures & 1105 & 1090 & 1923 & 638 & 1573 & 4043 & 17,175 & 27,547 & 35.45 \\
\hline Negative fungal cultures & 3149 & 1734 & 4424 & 1997 & 5908 & 6801 & 26,155 & 50,168 & 64.55 \\
\hline Total number of samples & 4254 & 2822 & 4072 & 2634 & 7472 & 10,844 & 49,133 & 77,716 & 100 \\
\hline
\end{tabular}

${ }^{1}$ Dermatophyte infections. ${ }^{2}$ Percentages in relation to the number of dermatophytes $(n=10,958)$ are in straight line characters. Percentages in relation to the total number of samples analyzed $(n=77,716)$ are in italics. 


\subsection{Dermatophytes Isolated from Animals}

459 dermatophytes were isolated from animal samples collected from 2008 to 2019 (Table 2) T. mentagrophytes was the most frequently isolated species from cats and dogs with a prevalence of $62.8 \%(n=169 / 269)$ and $61.0 \%(n=86 / 141)$, respectively. $M$. canis was less often isolated in these hosts with a prevalence of $36.8 \%(n=99 / 269)$ and $23.4 \%(n=33 / 141)$, respectively.

Table 2. Dermatophytes isolated in Lausanne from animal samples collected by veterinarians between 2008 and 2019.

\begin{tabular}{|c|c|c|c|c|c|c|c|}
\hline & Cats & Dogs & Guinea Pigs & Rabbits & Horses & Miscellaneous & Total \\
\hline T. mentagrophytes & 169 & 86 & 1 & 2 & $1^{1}$ & & 259 \\
\hline M. canis & 99 & 33 & & & & 1 (Cheetah) & 133 \\
\hline T. benhamiae & 1 & 4 & 35 & 1 & & 1 (Degu) & 42 \\
\hline N. persicolor & & 6 & & & & & 6 \\
\hline N. gypsea & & 12 & & & 2 & & 14 \\
\hline T. verrucosum & & & & & & 1 (Cattle); 1 (Swines) & 2 \\
\hline T. equinum & & & & & 2 & & 2 \\
\hline T. erinacei & & & & & & 1 (Hedgehog) & 1 \\
\hline Total & 269 & 141 & 36 & 3 & 5 & 5 & 459 \\
\hline
\end{tabular}

Overall, 35 among 36 dermatophytes isolated from Guinea pigs were T. benhamiae. This species was isolated four times from dogs and once from a cat, once from a rabbit and once from a rodent (degu). T. erinacei was isolated from a hedgehog and from a skin lesion of its owner, which resulted clinically in a highly inflammatory ringworm on the hand [16].

Species of the genus Nannizzia (N. persicolor and N. gypsea) were almost exclusively isolated from dogs.

Samples from livestock were generally not sent to our laboratory, which explains the low number of isolated T. verrucosum.

\section{Discussion}

The present study provides insights into the prevailing dermatophytes in Switzerland. It reveals the dominance of T. rubrum as reported in Europe since the nineties $[4,5,17,18]$, the incidence of T. violaceum and T. soudanense causing tinea capitis in patients of African and Mediterranean origin (mostly immigrants), and the appreciable frequency of T. mentagrophytes, T. benhamiae and M. canis as zoophilic species in the young Swiss autochthonous population.

The prevalence of anthropophilic dermatophytes has changed considerably since the beginning of the 20th century. T. rubrum, which was first described in 1910 (as Epidermophython rubrum) has developed during the second half of this century to become the dominant species causing dermatophytosis. On the other hand, the anthropophilic species M. audouinii, E. floccosum and T. schoenleinii were the main dermatophytes in the 19th and early 20th centuries, but their frequency has considerably decreased $[4,5]$. We compared the occurrence of dermatophytes and different ringworms from the present survey with data collected from 1967 to 1970 and from 1990-2000 in the same laboratory [17,19] (Table 3). While E. floccosum was still prevalent in the 1960s, representing $17 \%$ of dermatophytes isolated, this species now represents less than $0.5 \%$ in Lausanne. The incidence of M. audouinii was already low in the 1960s (Table 3). Furthermore, a marked difference in the prevalence of the zoophilic species T. verrucosum was observed. Whereas 10\% of dermatophytes isolated from 1967 to 1970 in Lausanne were T. verrucosum, the current analysis documents only $1 \%$ of this species among all isolated dermatophytes. The diminution of the incidence of $T$. verrucosum can be interpreted considering the decrease in the rural population. Regarding T. tonsurans, its frequency has always been low in Lausanne (about 1\%), while this species is prevalent in the USA [4]. To date, we have not registered any Indian patients with tinea corporis or tinea cruris caused by T. mentagrophytes type VIII. This particular 
genotype, which has reached European countries, is responsible for the current epidemic of tinea cruris and tinea corporis in India, where many cases are resistant to terbinafine [20].

Table 3. Prevalence of dermatophyte species (\%) from three different surveys during the last 50 years in Lausanne.

\begin{tabular}{|c|c|c|c|}
\hline & $\begin{array}{l}\quad 1967-1970 \\
\text { Gregoriu and Brot, } 1972 \text { [19] } \\
\qquad n=584\end{array}$ & $\begin{array}{c}1990-2000 \\
\text { Monod et al. } 2001[17] \\
n=4193\end{array}$ & $\begin{array}{c}2001-2018 \\
\text { This Study } \\
n=10,958\end{array}$ \\
\hline \multicolumn{4}{|c|}{ Anthropophilic species } \\
\hline T. rubrum & 35.1 & 62 & 60.07 \\
\hline T. interdigitale & $30.9^{1}$ & 15.6 & 20.14 \\
\hline T. tonsurans & 0.9 & 0.1 & 1.12 \\
\hline T. violaceum & 0.2 & 1.7 & 2.29 \\
\hline T. soudanense & 0.4 & 1.6 & 1.85 \\
\hline T. schoenleini & 0.5 & & \\
\hline E. floccosum & 17 & 1 & 0.36 \\
\hline M. audouinii & 0.4 & 2.3 & 1.68 \\
\hline M. ferrugineum & 0.4 & & \\
\hline \multicolumn{4}{|l|}{ Zoophilic species } \\
\hline T. verrucosum & 10.2 & 1.3 & 1.03 \\
\hline T. mentagrophytes & $30.9^{1}$ & 9.9 & 5.38 \\
\hline T. benhamiae & & & 1.27 \\
\hline T. quinckeanum & 0.2 & & \\
\hline \multicolumn{4}{|l|}{ T. equinum } \\
\hline \multicolumn{4}{|l|}{ T. erinacei } \\
\hline M. canis & 2.4 & 5 & 3.51 \\
\hline \multicolumn{4}{|l|}{ Geophilic species } \\
\hline N. gypsea & 2.5 & 0.2 & 0.52 \\
\hline N. persicolor & 0.2 & 0 & 0.05 \\
\hline
\end{tabular}

T. benhamiae was not recorded in the two previous surveys in Lausanne as elsewhere in the 20th century. This species, first described in 1967 by Ajello and Cheng [21] and clearly distinguished from T. mentagrophytes, was reported in our laboratory for the first time in 2003 [22]. With the increased number of Guinea pigs and rodents as domestic animals, T. benhamiae is now widespread in Europe and Japan [23].

Although human dermatophytoses are predominantly caused by anthropophilic species, zoonotic infections form a significant proportion of cases with T. mentagrophytes, M. canis. and T. benhamiae (Table 2). T. mentagrophytes was more prevalent than M. canis in contrast to most reports in southern Europe, where the latter is the main zoophilic species and causative agent of tinea capitis and tinea corporis [4,24-26]. The investigation of dermatophytes from animal samples showed that cats and dogs were reservoirs for T. mentagrophytes and M. canis, and Guinea pigs for T. benhamiae (Table 3). Cats with M. canis are usually domestic indoor cats while hunting cats, mainly European short-haired cats, and dogs are the reservoir of T. mentagrophytes [27]. Cats and dogs are most probably colonized or infected with $T$. mentagrophytes through contact with soil. It should be noted here that $T$. mentagrophytes encompasses various genotypes, which were not identified in our routine analyses. While several genotypes of T. mentagrophytes correspond to zoophilic dermatophytes identified in cats, dogs and rodents, a recent study in Germany has revealed that isolates of T. mentagrophytes causing pubic infections had a particular genotype (type VII), for which no animal source has been found so far. It is therefore possible that the cases of tinea cruris reported in this study are not of animal origin but of human origin [28].

Dogs have also been found to be infected with N. gypsea (geophile) and N. persicolor, which is considered a zoophilic species because it has been isolated from voles and shrews [12]. However, it is 
also very possible that the infection of dogs with N. persicolor could occur through contact with soil. The origin of T. erinacei in a patient could be traced to contact with a hedgehog [16], as was the case for several cases of this emerging dermatophyte species in Spain and Germany [29-32].

Knowledge of the epidemiology of dermatophytes can facilitate the prevention of dermatophytosis and intervention with prophylactic measures. Zoophilic dermatophytes apparently lose their pathogenicity and are less contagious after infecting humans [33], and most infections are acquired directly from animals. Therefore, the best preventive measure to avoid infection with a zoophilic species is to avoid direct contact with pets. It is important to accurately identify the fungus involved in inflammatory dematophytosis and to carefully examine pets as a possible source of infection.

Author Contributions: Conceptualization, M.M., E.G. and O.B.; Methodology, M.M. and O.B.; Laboratory analyzes, O.B., M.F. and K.S.; Writing_Original Draft Preparation, M.M.; Supervision, E.G. All authors have read and agreed to the published version of the manuscript.

Funding: This research received no external funding.

Acknowledgments: We thank Alexis Laurent, for his critical review of the manuscript and his help with the English language.

Conflicts of Interest: The authors declare no conflict of interest. No funding was received for this retrospective study, which was performed as parts of a program for epidemiological surveillance and of an internal quality control.

\section{References}

1. Baudraz-Rosselet, F.; Monod, M.; Jaccoud, S.; Frenk, E. Efficacy of terbinafine treatment of tinea capitis in children varies according to the dermatophyte species. Br. J. Dermatol. 1996, 135, 1011-1012. [CrossRef] [PubMed]

2. Mock, M.; Monod, M.; Baudraz-Rosselet, F.; Panizzon, R.G. Tinea capitis dermatophytes: Susceptibility to antifungal drugs tested invitro and in vivo. Dermatology 1998, 197, 361-367. [CrossRef] [PubMed]

3. Hay, R.J. Tinea capitis: Current status. Mycopathologia 2017, 182, 87-93. [CrossRef] [PubMed]

4. Seebacher, C.; Bouchara, J.P.; Mignon, B. Updates on the epidemiology of dermatophyte infections. Mycopathologia 2008, 166, 335-352. [CrossRef]

5. Zhan, P.; Liu, W. The Changing Face of Dermatophytic Infections Worldwide. Mycopathologia 2017, 182, 77-86. [CrossRef]

6. Monod, M.; Baudraz-Rosselet, F.; Ramelet, A.A.; Frenk, E. Direct mycological examination in dermatology: A comparison of different methods. Dermatologica 1989, 179, 183-186. [CrossRef]

7. Verrier, J.; Pronina, M.; Peter, C.; Bontems, O.; Fratti, M.; Salamin, K.; Schürch, S.; Gindro, K.; Wolfender, J.L.; Harshman, K.; et al. Identification of infectious agents in onychomycoses by PCR-terminal restriction fragment length polymorphism. J. Clin. Microbiol. 2012, 50, 553-561. [CrossRef]

8. Vanbreuseghem, R.; De Vroey, C.; Takashio, M. Guide Pratique de Mycologie Médicale et Vétérinaire; Masson: Paris, France, 1966; pp. 1-206.

9. Kwong-Chung, K.J.; Bennet, J.E. Medical Mycology; Lea \& Febiger: Philadelphia, PA, USA, 1992; pp. 1-806.

10. Ninet, B.; Jan, I.; Bontems, O.; Léchenne, B.; Jousson, O.; Panizzon, R.; Lew, D.; Monod, M. Identification of dermatophyte species by $28 \mathrm{~S}$ ribosomal DNA sequencing with a commercial kit. J. Clin. Microbiol. 2003, 41, 826-830. [CrossRef]

11. Symoens, F.; Jousson, O.; Packeu, A.; Fratti, M.; Staib, P.; Mignon, B.; Monod, M. The dermatophyte species Arthroderma benhamiae: Intraspecies variability and mating behavior. J. Med. Microbiol. 2013, 62, 377-385. [CrossRef]

12. de Hoog, G.S.; Dukik, K.; Monod, M.; Packeu, A.; Stubbe, D.; Hendrickx, M.; Kupsch, C.; Stielow, J.B.; Freeke, J.; Göker, M.; et al. Toward a novel multilocus phylogenetic taxonomy for the dermatophytes. Mycopathologia 2017, 182, 5-31. [CrossRef]

13. Symoens, F.; Jousson, O.; Planard, C.; Fratti, M.; Staib, P.; Mignon, B.; Monod, M. Molecular analysis and mating behaviour of the Trichophyton mentagrophytes species complex. Int. J. Med. Microbiol. 2011, 301, $260-266$. [CrossRef]

14. Stockdale, P.M. The Microsporum gypseum complex (Nannizzia incurvata Stockd., N. gypseum (Nann.) comb. nov., N. fulva sp. nov.). Sabouraudia 1963, 3, 114-126. [CrossRef] 
15. Chollet, A.; Wespi, B.; Roosje, P.; Unger, L.; Venner, M.; Goepfert, C.; Monod, M. An outbreak of Arthroderma vanbreuseghemii dermatophytosis at a veterinary school associated with an infected horse. Mycoses 2015, 58, 233-238. [CrossRef] [PubMed]

16. Perrier, P.; Monod, M. Tinea manuum caused by Trichophyton erinacei: First report in Switzerland. Int. J. Dermatol. 2015, 54, 959-960. [CrossRef] [PubMed]

17. Monod, M.; Jaccoud, S.; Zaugg, C.; Lechenne, B.; Baudraz, F.; Panizzon, R. Survey of dermatophyte infections in the Lausanne area Switzerland. Dermatology 2002, 205, 201-203. [CrossRef]

18. Gamage, H.; Sivanesan, P.; Hipler, U.C.; Elsner, P.; Wiegand, C. Superficial fungal infections in the department of dermatology, University Hospital Jena: A 7-year retrospective study on 4556 samples from 2007 to 2013. Mycoses 2020, 63, 558-565. [CrossRef]

19. Grigoriu, D.; Brot, A. La flore fongique isolée à Lausanne de 1067 à 1970 Fungal flora isolated in Lausanne from 1967 till 1970. Mykosen 1975, 18, 505-509. [CrossRef] [PubMed]

20. Nenoff, P.; Verma, S.B.; Vasani, R.; Burmester, A.; Hipler, U.C.; Wittig, F.; Krüger, C.; Nenoff, K.; Wiegand, C.; Saraswat, A.; et al. The current Indian epidemic of superficial dermatophytosis due to Trichophyton mentagrophytes-A molecular study. Mycoses 2019, 62, 336-356. [CrossRef]

21. Ajello, L.; Cheng, S.L. The perfect state of Trichophyton mentagrophytes. Sabouraudia 1967, 5, 230-234. [CrossRef]

22. Fumeaux, J.; Mock, M.; Ninet, B.; Jan, I.; Bontems, O.; Léchenne, B.; Lew, D.; Panizzon, R.; Jousson, O.; Monod, M. First report of Arthroderma benhamiae in Switzerland. Dermatology 2004, 208, 244-250. [CrossRef]

23. Nenoff, P.; Uhrlaß, S.; Krüger, C.; Erhard, M.; Hipler, U.C.; Seyfarth, F.; Herrmann, J.; Wetzig, T.; Schroedl, W.; Gräser, Y. Trichophyton species of Arthroderma benhamiae-A new infectious agent in dermatology. J. Dtsch. Dermatol. Ges. 2014, 12, 571-581. [PubMed]

24. del Boz, J.; Crespo, V.; Rivas-Ruiz, F.; de Troya, M. A 30-year survey of paediatric tinea capitis in southern Spain. J. Eur. Acad. Dermatol. Venereol. 2011, 25, 170-174. [CrossRef] [PubMed]

25. Tsoumani, M.; Jelastopulu, E.; Bartzavali, C.; Vamvakopoulou, S.; Dimitracopoulos, G.; Anastassiou, E.D.; Christofidou, M. Changes of dermatophytoses in southwestern Greece: An 18-year survey. Mycopathologia 2011, 172, 63-67. [CrossRef]

26. Otašević, S.; Momčilović, S.; Golubović, M.; Ignjatović, A.; Rančić, N.; Đorđević, M.; Ranđelović, M.; Hay, R.; Arsić-Arsenijević, V. Species distribution and epidemiological characteristics of superficial fungal infections in Southeastern Serbia. Mycoses 2019, 62, 458-465. [CrossRef]

27. Drouot, S.; Mignon, B.; Fratti, M.; Roosje, P.; Monod, M. Pets as the main source of two zoonotic species of the Trichophyton mentagrophytes complex in Switzerland, Arthroderma vanbreuseghemii and Arthroderma benhamiae. Vet. Dermatol. 2008, 20,13-18. [CrossRef] [PubMed]

28. Kupsch, C.; Czaika, V.A.; Deutsch, C.; Gräser, Y. Trichophyton mentagrophytes-A new genotype of zoophilic dermatophyte causes sexually transmitted infections. J. Dtsch. Dermatol. Ges. 2019, 17, 493-501. [CrossRef] [PubMed]

29. Schauder, S.; Kirsch-Nietzki, M.; Wegener, S.; Switzer, E.; Qadripur, S.A. Zoophile Dermatomykose durch Trichophyton erinacei bei 8 Patienten. Hautarzt 2007, 58, 62-67. [CrossRef]

30. Abarca, M.L.; Castellá, G.; Martorell, J.; Cabañes, F.J. Trichophyton erinacei in pet hedgehogs in Spain: Occurrence and revision of its taxonomic status. Med. Mycol. 2017, 55, 164-172. [CrossRef] [PubMed]

31. Kargl, A.; Kosse, B.; Uhrlaß, S.; Koch, D.; Krüger, C.; Eckert, K.; Nenoff, P. Igelpilze in einer Münchner Hautarztpraxis Fallbeschreibungen und Übersicht. Hautarzt 2018, 69, 576-585. [CrossRef]

32. Kromer, C.; Nenoff, P.; Uhrlaß, S.; Apel, A.; Schön, M.P.; Lippert, U. Trichophyton erinacei transmitted to a pregnant woman from her pet hedgehogs. JAMA Dermatol. 2018, 154, 967-968. [CrossRef]

33. Marples, M.J. The ecology of Microsporum canis Bodin in New Zealand. J. Hyg. 1956, 54, 378-387. [CrossRef] [PubMed]

(C) 2020 by the authors. Licensee MDPI, Basel, Switzerland. This article is an open access article distributed under the terms and conditions of the Creative Commons Attribution (CC BY) license (http://creativecommons.org/licenses/by/4.0/). 